\title{
The future of ice coring: International Partnerships in Ice Core Sciences (IPICS)
}

Edward J. Brook ${ }^{1}$, Eric WolfF ${ }^{2}$, Dorthe Dahl-Jensen ${ }^{3}$, Hubertus Fischer ${ }^{4}$, Eric J. Steig ${ }^{5}$, on behalf of the IPICS Steering Committee

'Dept. of Geosciences, Oregon State University, Corvallis, USA; brooke@geo.oregonstate.edu

${ }^{2}$ British Antarctic Survey, Cambridge, UK; ewwo@bas.ac.uk

${ }^{3}$ Niels Bohr Institute, University of Copenhagen, Denmark, ddj@gfy.ku.dk

${ }^{4}$ Alfred Wegener Institute, Bremerhaven, Germany; hufischer@awi-bremerhaven.de

${ }^{5}$ Dept. of Earth and Space Sciences, University of Washington, Seattle, USA; steig@ess.washington.ed

\section{Introduction: Goals of IPICS}

Ice cores provide information about past climate and environmental conditions on timescales from decades to hundreds of millennia, and direct records of the composition of the atmosphere. As such, they are cornerstones of global change research. For example, ice cores play a central role in showing how closely climate and greenhouse gas concentrations were linked in the past, and in demonstrating that very abrupt climate switches can occur. With the completion of major projects in Greenland and Antarctica over the last 15 years, the international ice coring community is planning for the next several decades. The costs and scope of future work create the need for coordinated international collaboration. Developing this international collaboration is the charge of IPICS, International Partnerships in Ice Core Sciences, a planning group currently composed of ice coring scientists, engineers, and drillers from 18 nations.

Two international meetings in 2004 and 2005 (Brook and Wolff, 2006) lead to an ambitious four-element framework that both extends the ice core record in time and enhances spatial resolution. The four projects were defined as:

1) A deep ice coring program in Antarctica that extends through the mid-Pleistocene transition, a time period where Earth's climate shifted from 40,000 year to 100,000 year cycles.

2) A deep ice core in Greenland recovering an intact record of the last interglacial period.

3) A bipolar network of ice core records spanning approximately the last 40,000 years.

4) A global network of ice core records spanning the last 2,000 years.
A fifth, and critical, element of IPICS is the development of advanced ice core drilling technology.

\section{The oldest ice core}

- A 1.5 million year record of climate and greenhouse gases from Antarctica

We currently live in the latest warm phase in a series of cold/warm oscillations occurring every 100,000 years. Ice core records show that for the last 650,000 years, carbon dioxide and other greenhouse gases have been closely linked to these climate cycles (Fig. 1). However, we still lack understanding of the natural regulation of carbon dioxide, and the amplifications that make the climate system so sensitive. Both of these factors are important as we try to predict the future.

Furthermore, our oldest ice core, from the European Project for Ice Coring in Antarctica (EPICA), extends back 800,000 years into the past. However, we know that just before this time, the characteristic frequency of climate variability was different, with cycles of 40,000 years (Fig. 1). The origin of this shift is a major puzzle. Studying the interactions of climate and biogeochemistry during and before the transition will allow us to:

- Understand the natural variability that has led to our current climate.

- Test the hypothesis that the change from 40,000 to 100,000 year cycles was caused by a lowering of atmospheric carbon dioxide concentrations.

- Better understand the timescales and processes that control exchange of carbon dioxide (including excess $\mathrm{CO}_{2}$ from human activities) between reservoirs, and the links between climate and the natural cycles of gases such as methane, and of terrestrial and marine aerosols.

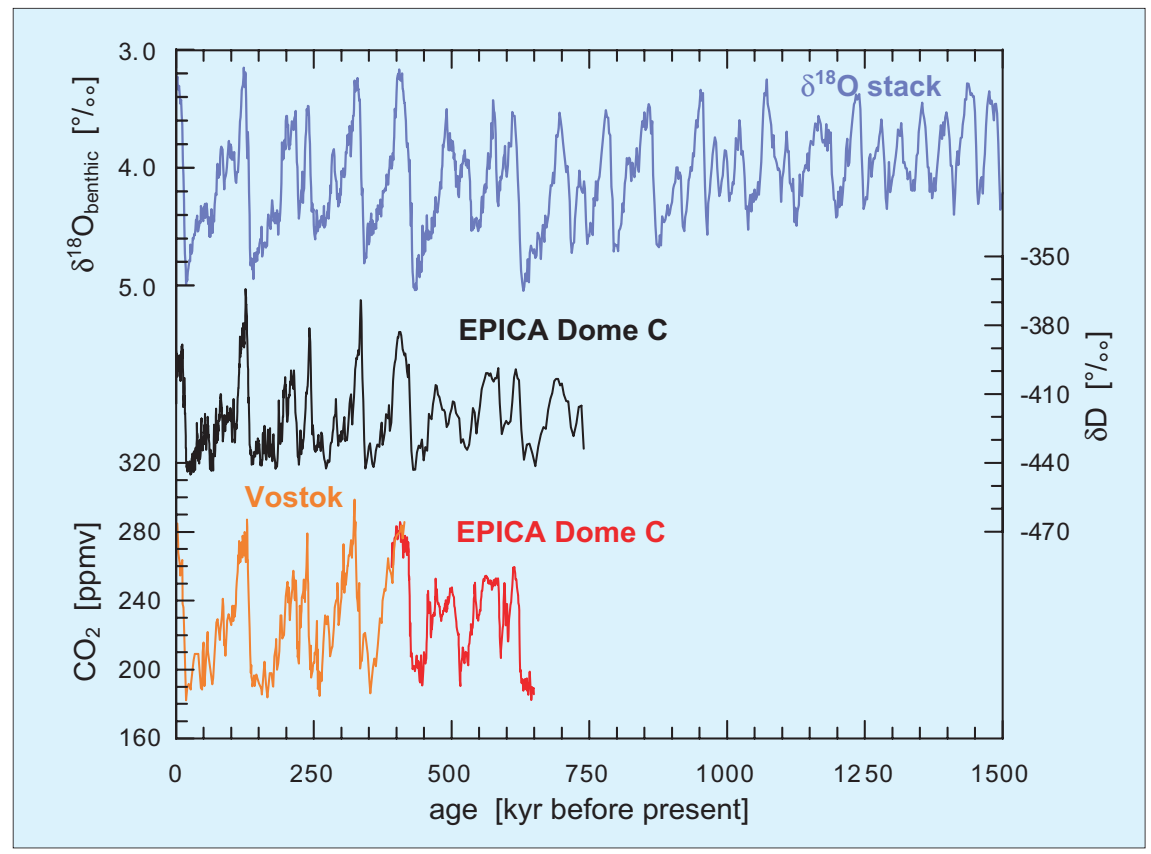

Fig. 1: Top: benthic oxygen isotope stack from Lisiecki and Raymo (2005) showing the shift from $40 \mathrm{ka}$ to $100 \mathrm{ka}$ global climate cycles in the mid-Pleistocene. Middle: EPICA Dome C stable isotope record showing the evolution of central east Antarctic climate for the last 800,000 years (EPICA community members, 2004). Bottom: $\mathrm{CO}_{2}$ record from the Vostok (Petit et al., 1999) and Dome C ice cores (Siegenthaler et al., 2005). 


\section{Program News: Ice Core Science}

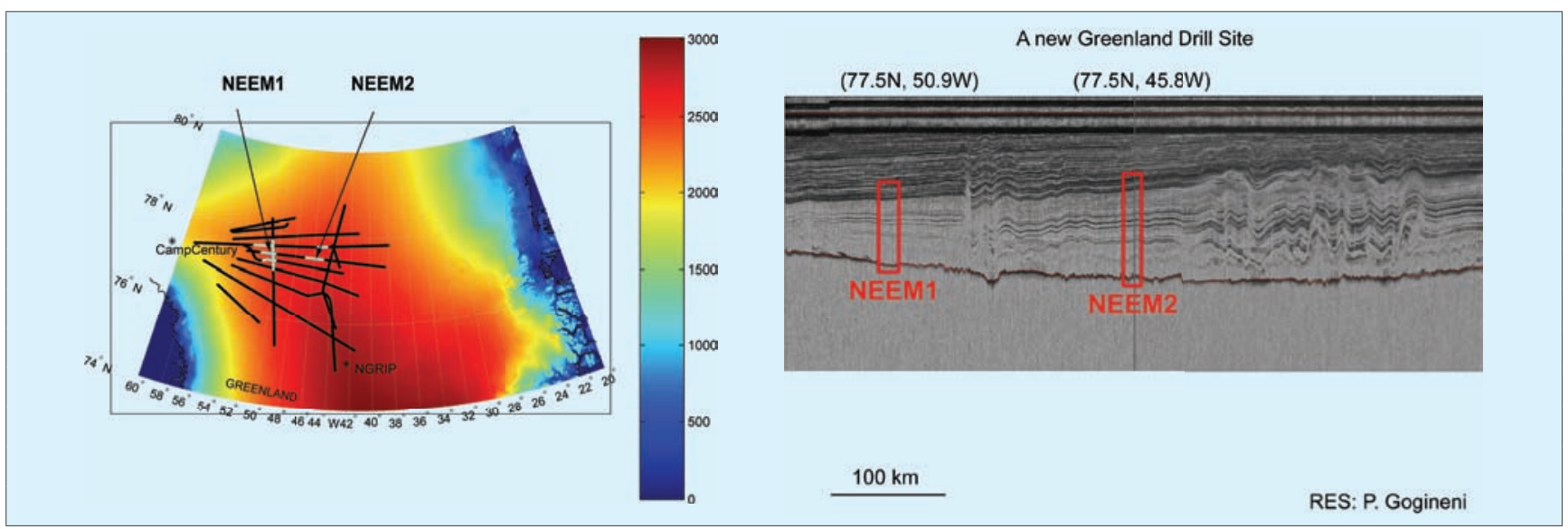

Fig. 2: Left: Surface elevation ( $m$ ) of the northern section of the Greenland ice sheet (Bamber et al., 2001) and radar echo sounding section from NEEM 1 to NEEM 2 (http://tornado.rsl.ku.edu/Greenlanddata.htm). NEEM 1 is the likely location of the new core in NW Greenland.

To accomplish these objectives, we need to obtain a reliable ice core record of climate and biogeochemistry extending through several of the 40,000 year cycles and up to the present. This requires that we produce a replicated record extending at least 1.2 million and, preferably, 1.5 million years into the past.

Undoubtedly, ice older than 800,000 years does exist in the Antarctic ice sheet. The first task will be to carry out an iterative process of modeling and survey to identify possible sites in the relatively littlesurveyed interior of East Antarctica, where accumulation rates are low and ice thickness is high. Observation of internal radar layers, allowing us to follow layers of known age from existing drill sites, will be critical.

The drilling itself poses no unique technical challenges, apart from extremely cold conditions, but will require a significant logistical effort. Some required survey work is already planned for the International Polar Year (IPY; 2007-2008). IPICS will assess the results of this work in order to recommend one or more target drilling sites. Many recent major ice core projects have been multinational, and we anticipate that the pooled survey, drilling, analytical and intellectual capacity of all the major players will be needed to achieve the Oldest Ice project.

IPICS will now start drawing up plans for how to implement the project, with drilling starting early in the next decade.

\section{The last interglacial and beyond}

- A northwest Greenland deep ice core drilling project

Greenland ice cores provide a compelling picture of the abrupt, milIennial-scale, climatic flips of the last glacial period (DansgaardOeschger events). Understanding the cause of these events, and their implications for future change, is one of the hottest topics in climate studies, with significant policy implications. However, the existing Greenland cores are deficient in one important respect. The last interglacial (Eemian) has proved to be a difficult target; even in the most recent NorthGRIP core (NGRIP Members, 2004), the Eemian record was incomplete due to basal melting.

The last interglacial period is critical because it appears to have been warmer than the present, allowing us to see what happens in a climate like the one we are approaching. Models suggest that the Greenland ice sheet will waste away under warmer conditions; the last interglacial provides a test of such models. Supplementing existing low-resolution records from other archives, a new Greenland ice core would indicate the character of the Eemian in the North Atlantic region and allow us to:

- Chart the full course of an interglacial from termination to inception at very high resolution.

- Determine if rapid climate changes occurred in such a warmer climate or in the preceding glacial period.

- Relate climate variations from the present and the last interglacial period to the predicted scenarios under global warming.
IPICS plans to obtain a reliable highresolution Greenland ice core record of the onset of the Eemian period and possibly the previous glacial perioda record of at least 140,000 years. The first step is to identify a suitable site, where the full Eemian period is present and not disturbed by flow. Based on radio echo sounding profiles produced by the University of Kansas, the team at the University of Copenhagen has deduced that the most likely candidate area is in northwest Greenland (Fig. 2). They traced internal layers dating back to 82,000 years before present to a preferred site where the ice is $2542 \mathrm{~m}$ thick, and the Eemian section is estimated to be $80 \mathrm{~m}$ thick, with no signs of folding or other problems.

IPY is a target for the start of the deep Greenland drilling. The logistical, technological and scientific challenges require an international effort that builds on the successful North GRIP program, and scientists from several nations have already expressed interest in participating.

\section{The IPICS 40,000 year network}

- A bipolar record of climate forcing and response

Recent paleoclimate reconstructions clearly document that the Earth's climate is an intricate interplay of oceanic, atmospheric, biogeochemical, and cryospheric processes. However, the reasons for changes in greenhouse gas concentrations and aerosol loads, sea-level and ice masses, as well as their coupling to atmospheric and ocean circulation, are still not sufficiently understood. Previous ice core records from cen- 
tral Greenland and East Antarctica defined the overall features of glacial and interglacial periods and transitions between them, and the characteristics of rapid climate change during the last ice age, at a few individual sites. However, the spatial evolution of deglaciation and abrupt climate change, particularly differences between northern and southern hemisphere patterns, and the processes responsible for those changes, cannot be diagnosed from single locations. The IPICS 40,000 year network of temporally synchronized, high-resolution ice cores from both polar regions will provide data needed to decipher climate change mechanisms. The focus is on the last 40,000 years because this period includes the major Earth System reorganizations of the last glacial-interglacial transition, climate variations of the Holocene, and the well-dated and documented sequence of abrupt climate changes in marine isotope stage 3 (Fig. 3). The 40,000 year network will:

- Determine spatial patterns in environmental parameters related to ocean surface conditions (e.g. sea ice and marine biological productivity).

- Construct the sequence of events from 40,000 years to present in different geographic areas of both polar regions at the highest resolution possible.

- Synchronize the new records using high-resolution measurements of $\mathrm{CH}_{4}, \mathrm{CO}_{2}$, and dust, as well as isotopic compositions of air components.

- Quantify the spatial and temporal evolution of rapid climate changes in both polar regions.

- Identify climate modes and teleconnection patterns under different climate boundary conditions (orbital forcing, greenhouse gas concentration, land ice masses). In addition, we need to understand the response of the ice sheets to climate change. Ice sheet models differ in predictions of the extent and thickness of the major ice sheets at the Last Glacial Maximum, and their contribution to global sea level. With the expansion of the ice sheets dur-

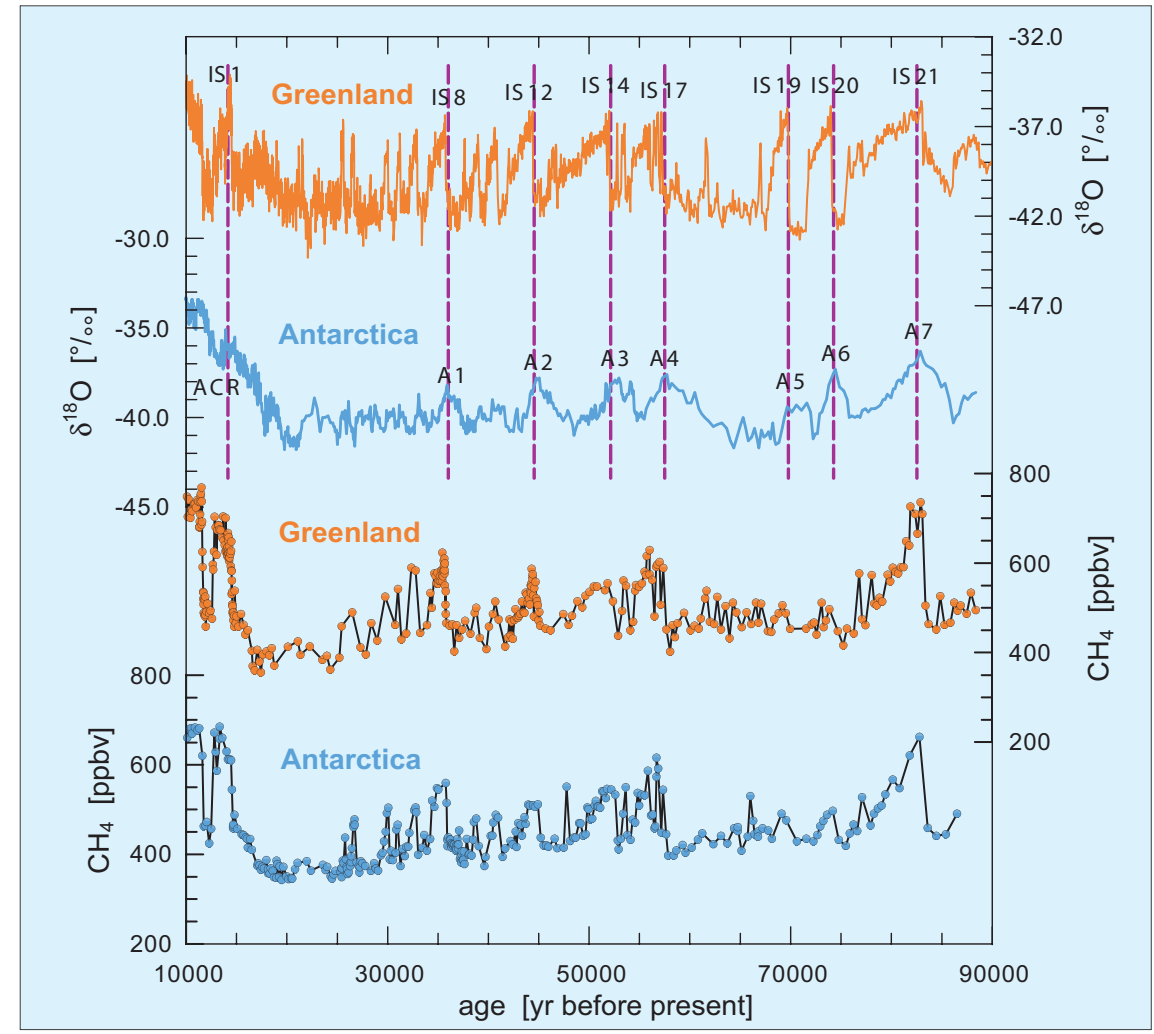

Fig. 3: Comparison of climate records from Antarctica and Greenland covering the last 90,000 years. The last 40,000 years is the best documented time period of both abrupt shifts in climate in both hemispheres, and the large change from glacial to interglacial conditions. From Blunier and Brook (2001).

ing the glacial period, some modern coastal ice domes may have merged with the inland ice. Ice cores from these locations can provide basic information (snow accumulation, temperature, altitude, ice sheet extent) on changes in the mass balance of ice caps and ice sheets.

A site selection team will identify optimal new core sites and coordinate cooperation between individual coring projects. A science plan will be developed to ensure that comparable data sets will be available for all drill sites, and to coordinate efforts for process-related studies in parallel to the deep ice core drilling. Two new sites have already been identified and will be completed in the near future: WAIS Divide (see Severinghaus, this issue) and Talos Dome (see Morgan, this issue). Further cores will complete the network over the following decade.

\section{The IPICS $2 \mathrm{k}$ array}

- A network of ice core climate and climate forcing records for the last two millennia.

Climate variability on decadal to century timescales is too low in frequency to be assessed from the instrumental record, and too spatially heterogeneous to be adequately characterized by the small number of existing highly resolved, well-dated paleoclimate records. For example, temperature reconstructions for the past thousand years remain widely debated because there are insufficient data prior to about AD 1600. The spatial and temporal variability of past precipitation, atmospheric circulation, and sea ice extent on these timescales remains even less well known. Similarly, while greenhouse gas concentrations are globally well mixed and can be determined from a small number of records, variations in important climate feedback variables, such as continental dust and pollution aerosol concentrations, are highly regional. Improved reconstructions of all of these variables are needed to answer fundamental questions about the natural variability of the climate system, and to put potential anthropogenic climate change in context.

Polar regions and high altitudes are especially poorly represented. Recent work under the International Trans Antarctic Scientific Expedition 


\section{Program News: Ice Core Science}

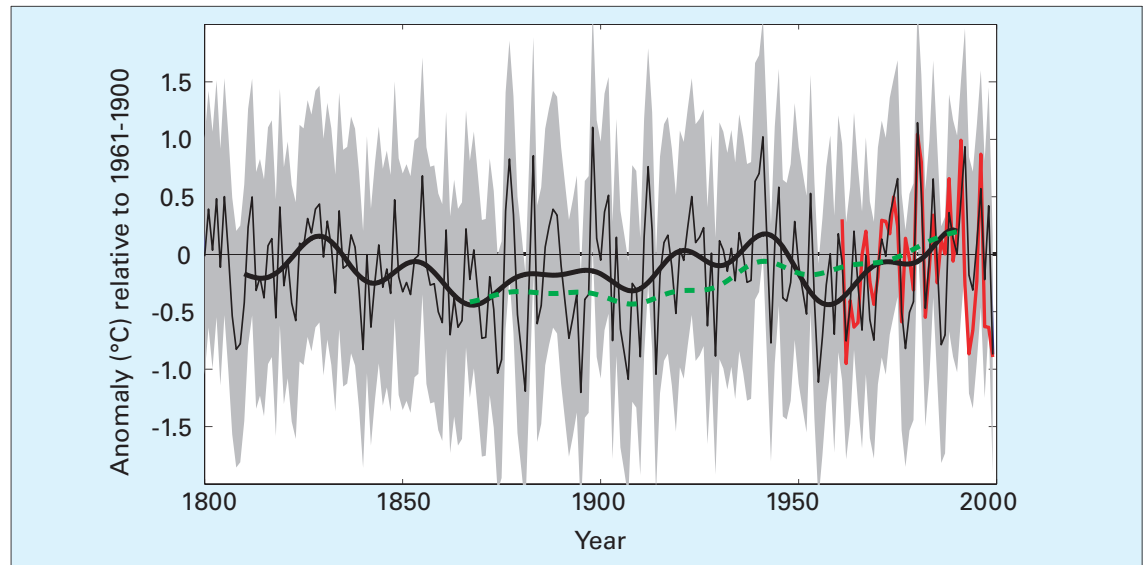

Fig. 4: Reconstructed continent-wide average Antarctic temperature anomalies from calibrated ice core stable isotope records. Black lines show annual data, 20-year smoothing (bold), and 2s (annual) uncertainties. Also shown for comparison are annual average Antarctic temperatures from instrumental data (red), and 20-year smoothed instrumental records of Southern Hemisphere temperature (dashed green). After D.P. Schneider, PhD thesis, University of Washington, 2005.

(ITASE) program in Antarctica (see Mayewski, this issue) demonstrated the feasibility of obtaining quantitative climate reconstructions on these timescales, given sufficient number and distribution of highly resolved records (Fig. 4).

However, most existing ice core records have inadequate temporal resolution, are too short to allow for quantitative reconstructions greater than one or two centuries in length, or do not overlap with modern satellite observations. The IPICS 2k Array will provide a larger network of ice cores, extending high altitude and high latitude proxy climate and climate forcing observations to the last two millennia. The target time frame of two thousand years (2k) includes both the industrial era and a long enough prior period to allow statistically meaningful assessment of natural century-scale variability. This will provide an ice core contribution to the global climate reconstructions being presented to policymakers. Important criteria for records in the IPICS 2k Array include:

- The highest possible resolution, and precise and accurate dating.

- Spatial distribution that captures the dominant patterns of climate variability.

- Multiple data sets from each core, to enable combination of multiple records in statistically meaningful reconstructions.

The IPICS 2k Array will build on results from previous and ongoing ice core networks, including the dozens of ice cores collected in Greenland (see McConnell, this issue) and on the Arctic islands, in Antarctica, and from high mountains at lower latitudes. While many of these records are only $100-200$ years in length, they can provide guidance for the selection of new drilling locations. At other locations, existing long records will need to be updated because many provide only limited information after the 1970s (when satellite measurements began), hampering calibration.

Compilation and analysis of existing data will be an important part of the effort, including improved statistical analyses and the use of tracer-enabled general circulation models. International planning and logistics cooperation for core collection and analysis will be needed. Archiving data at a single World Data site is planned.

\section{Ice core drilling technology}

- Improvements in drilling technology are needed to accomplish the IPICS goals.

Major issues include finding a replacement for commonly used drilling fluid components being phased out for environmental reasons, developing a system for replicate coring from the same ice core borehole, and drilling in relatively warm ice proved difficult in a number of recent projects. A fluid that will allow drilling in very cold ice in East Antnear the bed/ice interface, which has arctica, where the longest ice core records are expected, is a particular need, currently being addressed by drilling engineers. Lightweight drills capable of drilling to perhaps 1000 $\mathrm{m}$, and deployed without heavy logistics loads, will also be important.

\section{Implementing IPICS}

A major purpose of the IPICS2 meeting in Brussels (October 2005) was to establish consensus around the four IPICS projects, and to develop a steering committee and timeline for future work. At this meeting also representatives from PAGES (Past Global Changes) and SCAR (Scientific Committee on Antarctic Research) participated and a formal relationship between IPICS and these organizations is currently discussed. With the consensus in hand, writing teams have finalized "white paper" documents for each project, and are now moving on to developing detailed science and funding plans (for details of the white papers see http:// www.pages-igbp.org/ipics). A steering committee with representatives from all the nations involved has been formed, and a third meeting is planned within the next year or two to discuss and adopt the science plans. Initial stages of IPICS projects should be underway by then, and the scientific community can look forward to a richer spectrum of ice core data in the future.

\section{Project facts}

Project: International Partnership in Ice Core Sciences (IPICS)

Contact: Ed Brook (brooke@geo.oregonstate. edu), Eric Wolff (ewwo@bas.ac.uk)

Participants: Scientists from Australia, Belgium, Canada, China, Denmark, France, Germany, Italy, Japan, Korea, Netherlands, New Zealand, Norway, Russia, Sweden, Switzerland, United Kingdom, United States.

Funding: Support for planning from US NSF and European Polar Board. Support for projects to be sought from national agencies.

Where: Global

When: 2006 and following 1-2 decades

What: Comprehensive international ice coring program on all available timescales, multiparameter data sets

Web page: www.pages-igbp.org/science/ initiatives/ipics/ 


\section{REFERENCES}

Bamber, J. L., Ekholm, S. and Krabill, W.B., 2001: A new, high-resolution digital elevation model of Greenland fully validated with airborne laser altimetry, Journal of Geophysical Research, 106(B4): 6733-6746, 10.1029/2000JB900365

Blunier, T. and Brook, E.J., 2001: Timing of millennialscale climate change in Antarctica and Greenland during the last glacial period, Science 291: 109-112.

Brook E. and Wolff, E., 2006: The future of ice core science, EOS, 87 (4): 39.

EPICA-community-members, 2004: Eight glacial cycles from an Antarctic ice core, Nature, 429: 623-628.
Lisiecki, L. E., and Raymo, M.E., 2005: A Pliocene-Pleistocene stack of 57 globally distributed benthic $\delta^{18} 0$ records, Paleoceanography, 20, doi:10.1029/.

NGRIP Members, 2004: High resolution record of northern hemisphere climate extending in to the last interglacial period, Nature, 431: 147-141.

Petit, J. R., Jouzel, J., Raynaud, D., Barkov, N.I., Barnola J.-M., Basile, I., Bender, M., Chappellaz, J., Davis, M., Delaygue, G., Masson-Delmotte, V., Kotlyakov, V.M., Legrand, M., Lipenkov, V.Y., Lorius, C., Pepin, L., Ritz, C., Saltzman, E., and Stievenard M., 1999: Climate and atmospheric history of the past 420,000 years from the Vostok ice core, Antarctica, Nature, 399: 429-436.
Schneider, D.P., 2005: Antarctic climate of the past 200 years from an integration of instrumental, satellite and ice core proxy data, Ph.D. Thesis, University of Washington, 2005

Siegenthaler, U., Stocker, T. F., Monnin, E., Lüthi, D. Schwander, J., Stauffer, B., Raynaud, D., Barnola J. -M., Fischer, H., Masson-Delmotte, V. and Jouzel, J. 2005: Stable carbon cycle-climate relationship during the late Pleistocene, Science, 310: 1313-1317.

\section{The sea-floor drill rig "MeBo": Robotic retrieval of marine sediment cores}

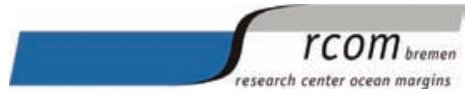

Tim Freudenthal and Gerold Wefer

Research Center Ocean Margins, University of Bremen, Germany; freuden@rcom-bremen.de, gwefer@rcom-bremen.de

Retrieval of marine sediment cores is conventionally carried out either by gravity coring or by drilling from a ship. Although a number of research vessels allow for gravity coring, the length of the retrieved cores is often shorter than desired. While this limitation can be overcome by drilling into deep-sea sediments, the availability and cost of drill-ships imposes a severe limitation on this approach. To bridge this gap in sediment-coring techniques, we developed a remotely operated underwater drill rig "MeBo" ("Meeresboden-Bohrgerät"; German for "sea-floor drill rig"). This portable drill can be operated from research vessels of opportunity. It is deployed on the sea floor and is capable of retrieving 50-m-long cores from sediments and hard rocks.

The drill is an electro-hydraulic system that is remotely controlled from the ship (Fig. 1). A steel armored umbilical with a diameter of $32 \mathrm{~mm}$ is used to lower the 10-tonheavy device to the sea bed, where four legs arm out in order to increase the stability of the rig. Copper wires and fiber optic cables within the umbilical supply energy from the vessel and allow communication between the MeBo and the control unit on deck. The system utilizes commercial rotary core barrels with diamond or tungsten carbide bits, as well as push coring barrels, and can set a casing as needed for various lithologies. The MeBo stores drilling rods and casing tubes, as well as push-coring and rotary barrels, on two rotating magazines that can be loaded with a

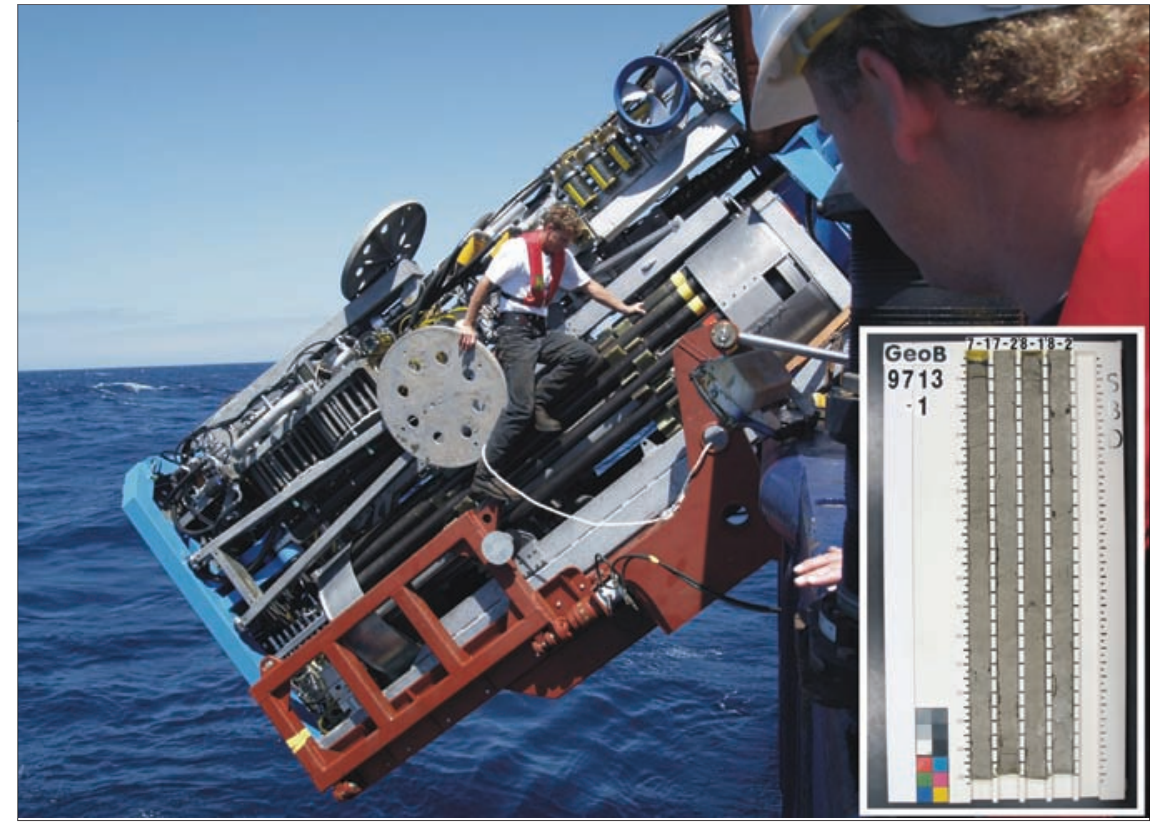

Fig. 1: Last checks on the newly developed sea-floor drill rig MeBo before the first deep-water test from the German research vessel METEOR. (Inset) Consolidated Pliocene marls retrieved by rotary drilling with the MeBo in $1700 \mathrm{~m}$ water depth off NW Africa.

mixture of tools specifically required for a drill job. The drill string is composed of 3-m sections. The MeBo has the capability to drill up to $50 \mathrm{~m}$ into the sea floor, to recover cores with 74-84 $\mathrm{mm}$ diameter, and to stabilize the drilled hole to a depth of $40 \mathrm{~m}$. The complete MeBo system, including drill, winch, launch and recovery system, control unit, as well as workshop and spare drill tools, is shipped within six 20' containers.

The MeBo was successfully tested on two cruises, from the research vessels METEOR (at the continental slope off NW Africa; cruise M65-3) and CELTIC EXPLORER (near the island of Rügen in the southern Baltic Sea; cruise CE0511). During theses tests, the MeBo was deployed ten times in 25-1700 m water depth, with a maximum drill depth of $23.65 \mathrm{~m}$. In total, about $105 \mathrm{~m}$ were drilled in sand, unconsolidated and consolidated marls, as well as glacial till. The total core length recovered was about $50 \mathrm{~m}$. Especially in cohesive sediments, a recovery rate of nearly $100 \%$ was achieved.

A major advantage of the MeBo compared to drill ships is that the drilling operations are independent of any ship movements due to waves, wind or currents. This allows the recovery of non-fractured cores of high quality (Fig. 1, inset). 